\title{
Re-Assembly of Archaeological Massive Limestones Using Epoxy Resin Modified with Nanomaterials-Part 2: Applied
}

\author{
Mohammad A. Aldoasri1 ${ }^{*}$, Sawsan S. Darwish², Mahmoud A. Adam², \\ Nagib A. Elmarzugi ${ }^{3}$, Sayed M. Ahmed ${ }^{4}$
}

\begin{abstract}
${ }^{1}$ National Nanotechnology Research Center, King Abdulalziz City for Science and Technology (KACST), Riyadh, KSA
${ }^{2}$ Department of Conservation, Faculty of Archaeology, Cairo University, Giza, Egypt

${ }^{3}$ Faculty of Pharmacy, Tripoli University and National Nanotechnology Project, Biotechnology Research Center, LARST, Tripoli, Libya ${ }^{4}$ Ministry of Antiquities, The Grand Egyptian Museum, Giza, Egypt

Email: ‘hafezm762000@yahoo.com, sawsansd@hotmail.com,nelmarzugi@gmail.com, sayedmansour32@yahoo.com
\end{abstract}

How to cite this paper: Aldoasri, M.A., Darwish, S.S., Adam, M.A., Elmarzugi, N.A. and Ahmed, S.M. (2020) Re-Assembly of Archaeological Massive Limestones Using Epoxy Resin Modified with Nanomaterials-Part 2: Applied. Green and Sustainable Chemistry, 10, 72-90.

https://doi.org/10.4236/gsc.2020.103006

Received: May 22, 2020

Accepted: August 25, 2020

Published: August 28, 2020

Copyright $\odot 2020$ by author(s) and Scientific Research Publishing Inc. This work is licensed under the Creative Commons Attribution International License (CC BY 4.0).

http://creativecommons.org/licenses/by/4.0/

(c) (i) Open Access

\begin{abstract}
This part of study represents the applied study; which is a continuation of the experimental study that was carried out in part 1 [1]. The experimental study in part 1 focused on evaluation of the effectiveness of Montmorillonite clay, calcium carbonate, and silicon dioxide nanoparticles for enhancing the performances of epoxy adhesives used in re-assembly of archaeological massive limestones. Based on the obtained results in part 1, the choice fell on epoxy-clay nanocomposites as the best re-assembly adhesive material reinforced with Stainless Steel to conduct the applied study project. The current applied study that represents a big project was carried out on 3 archaeological pharaonic massive limestones discovered separately in Ain Shams (Heliopolis) archaeological area in Egypt. The methodology included an accurate archaeological study, followed by analytical, and then the restoration and reassembly process. Firstly; in order to prove whether these artifacts are complementary to each other or not, then with a view to re-assembly and conserving these artifacts in the form of one stone block to be ready for museum display. Referred to the comprehensive archaeological and analytical study of the mentioned archeological stones, the results confirmed that, these stone pieces, in the original were one piece, therefore, it is possible to regrouping again to become one block complementary to each other, and this is what was done in this study.
\end{abstract}

\section{Keywords}

Epoxy-Clay Nanocomposites, Re-Assembly, Pharaonic Massive Stones, 
Analytical Study, Stainless Steel Bars

\section{Introduction}

The studied archaeological limestone blocks were discovered separately in Ain Shams (Heliopolis) archaeological area, one of the most famous ancient sites in Egypt [2], through the excavations of the Egyptian Mission Affiliated to the Egyptian Ministry of Antiquities during the excavation of the Marj prison farm area. Once the three stone objects "blocks" were discovered, the site's archaeologists documented and registered them by giving the so-called (site record number), the numbers for the three objects were $(94,95,96)$ (See Figures 1-3). After that, the stone objects were transferred to conservation center laboratories of the Grand Egyptian Museum, where the applied study was carried out.

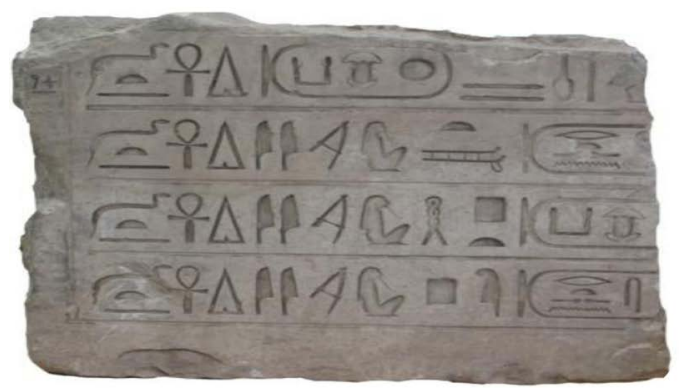

Figure 1. Discovered stone object No (94).

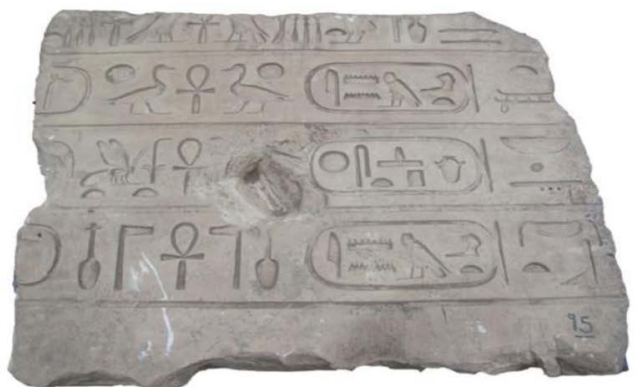

Figure 2. Discovered stone object No (95).

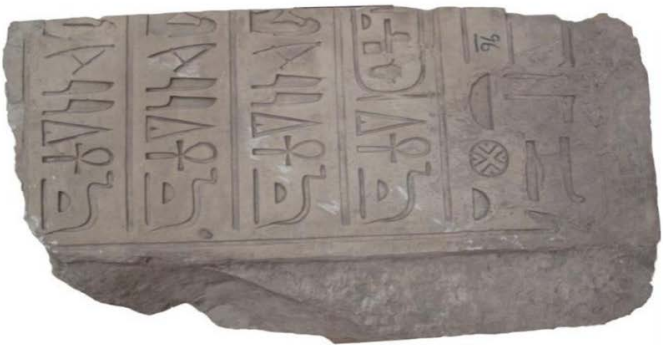

\begin{tabular}{|c|c|}
\hline Maximum length & $90 \mathrm{~cm}$ \\
\hline Width & $55 \mathrm{~cm}$ \\
\hline Maximum thickness & $21 \mathrm{~cm}$ \\
\hline The weigh & $260 \mathrm{~kg}$ \\
\hline
\end{tabular}

\begin{tabular}{|c|c|}
\hline Maximum length & $74 \mathrm{~cm}$ \\
\hline Width & $62 \mathrm{~cm}$ \\
\hline Maximum thickness & $21 \mathrm{~cm}$ \\
\hline The weigh & $210 \mathrm{~kg}$ \\
\hline
\end{tabular}

\begin{tabular}{|c|c|}
\hline Maximum length & $77 \mathrm{~cm}$ \\
\hline Width & $67 \mathrm{~cm}$ \\
\hline Maximum thickness & $21 \mathrm{~cm}$ \\
\hline The weigh & $180 \mathrm{~kg}$ \\
\hline
\end{tabular}

Figure 3. Discovered stone object No (96). 
Once the three stone objects were received, the teamwork conducted the photographic and architectural documentation and recorded the dimensions and weights. The three pieces were placed next to each other (See Figure 4) and through visual examination, the team noted the possibility that these three pieces although they were discovered separately from each other, and downloaded it different registration numbers, they may originally be one piece complementary to each other, or part of a wall, and it may have been separated through excavations, or through transferring processes or "breakage" as a result of being exposed to pressures that may be caused by their presence under the soil, or broken as a result of different mechanical deterioration factors.

Hence, the idea of conducting this research and applied project is to study and reassembly of these stone blocks. The current study project included an accurate archaeological study, followed by analytical, and then the restoration and reassembly process of the three stone objects were carried out.

The reassembly process of the stone blocks was carried out using special tools for dealing with massive archaeological stones, in addition to use Epoxy-Clay nanocomposites as an adhesive material for reassembly purpose according to the obtained results in an experimental study (Explained in Part 1), with the use of Stainless steel bars to strengthen and tighten the process of reassembly of stone blocks each other.

\section{Materials and methods}

\subsection{Structural Adhesive Methodology}

According to the obtained results in part 1, the experimental study approved and confirmed the epoxy-clay nanocomposites as the best re-assembly adhesive material can be used in re-assembly of massive stone objects. The properties of all used chemical materials (epoxy resin PY 1092-1 and its hardener HY 1092, the Montmorillonite Nano clay, and preparation of polymer-nanocomposites were explained in details in part 1). Epoxy resin PY 1092-1 and its hardener was purchased from (Huntsman Advanced Materials Ltd, Basel, Switzerland), commercially

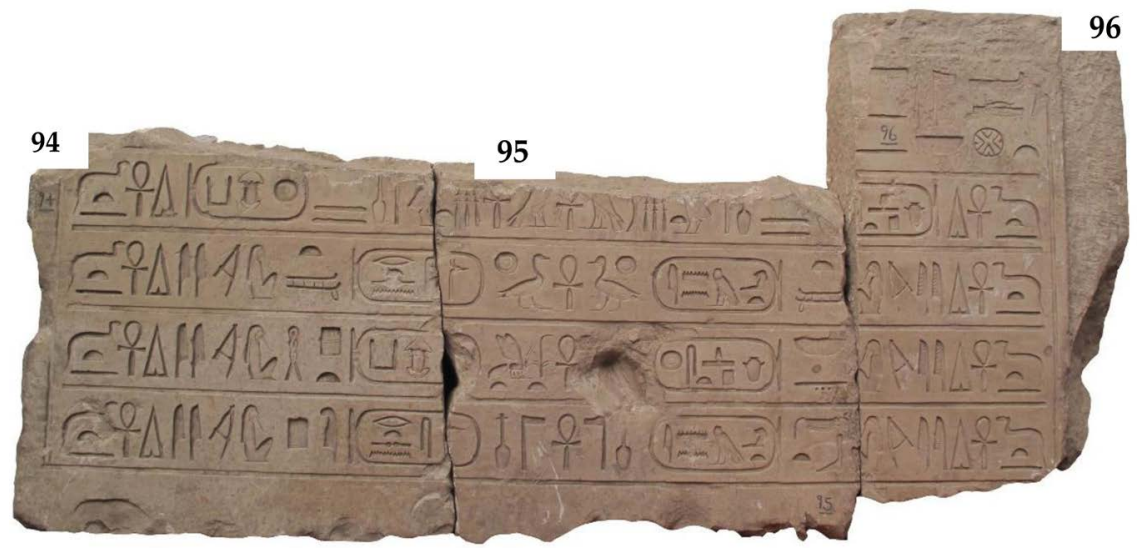

Figure 4. The three stone objects after being placed next to each other in the laboratory. 
known as Araldite ${ }^{\circledR}$ Precision. The Montmorillonite Organo-modified Nano clay (cloisite 30B), with particle diameter average $<50 \mathrm{~nm}$, were produced and characterized by Nanografi Nanoteknoloji company-Ankara, Turkey.

The use of stainless steel bars as reinforcing materials with the adhesive material in re-assembly processes [3] to strengthen and tighten the process of reassembly of stone blocks each other. Diameter of used metal bars $12 \mathrm{~mm}$, knowing that the number of used metal bars, the thickness of the bars, and the depth of the hole inside the stone to insert the bars depends mainly on the weight and thickness of the stone piece to be assembled, as well as the state of the stone to be combined [4]. The stainless steel bars have been cut and equipped to work in the process of collecting the stone blocks, according to the sizes and thickness that have been defined, and a preliminary experiment has been made on controlling it and inserting it into the holes that were executed with the stone, before the final assembly (Stainless steel metal bars supplied by CTS Company, Rome, Italy).

\subsection{Archaeological Study}

The archaeological study of stone blocks has started with the translation of surface inscriptions, followed by the analysis and documentation of the cartridges and hieroglyphic texts on the surface, and ended with the process of matching the existing writings with each piece, in order to ensure the compatibility of these pieces with each other.

\subsection{Analytical Study}

The examination and analysis were carried out on the stone objects to confirm the results obtained in archaeological study, and to identify the properties of studied stone and the existing deterioration aspects.

Polarizing Microscope PLM thin sections samples for identification of stone minerals, Scanning Electron Microscope SEM equipped with Energy Dispersive $\mathrm{X}$ Ray Spectroscopy (SEM+EDX) were performed to detect the element contents of archaeological limestone samples, X-Ray Diffraction (XRD) identification of the mineral composition of the samples was conducted by X-ray diffraction patterns.

\subsection{Re-Assembly and Conservation Processes}

Re-assembly and conservation processes are continuation of the archaeological and analytical studies that were carried out on stone objects. Based on the results of archaeological and analytical study, which confirm that these pieces of stone in the original was one piece, and it is possible to regrouping again to become one block complementary to each other, This stage was divided into two steps:

First: The reassembly process was carried out at the heavy artifacts conservation lab, at the conservation center of the Grand Egyptian Museum, and were initiated after a series of preliminary studies included accurate visual examination, studying the breaking edges between each piece and the other, matching 
the edges of the pieces together and studying the compatibility of hieroglyphics texts with each other. Moreover, architectural documentation of the stone objects using AutoCAD program. After that, the reassembly process of the stone blocks was done using special tools for dealing with heavy stone artifacts such as (Gate crane, chain block, special slings, and laser scale). All re-ssembly Tools (Chain block, laser scale, slings, Wheels, small crane, wood, and Skis) were supplied by conservation laboratories of grand Egyptian museum, Egypt.

Second: the conservation processes of the stone objects which include (photographic documentation before, during, and after conservation-mechanical and chemical cleaning to remove any stains from the stone surface-consolidation of weak and degraded of stone surface), and proposals of preparing objects for museum display.

\section{Results and Discussion}

\subsection{Results of Archaeological Study}

The archaeological study was carried out in cooperation with experts in the archaeological texts, and focused on the archaeological description of stone objects, and its superficial inscriptions and writings, translation of the surface inscriptions and their conformity with each other, to conduct a comprehensive archaeological description of the cartridges and the method of writing to find out whether these texts and writings are complementary to each other Some or not.

\subsubsection{Translation of Hieroglyphs and Surface Texts}

The archaeological study of the hieroglyphic texts revealed that the stone object No. 94 complements the artifact No. 95 (See Figure 5) it is showed that:

- The King (Senusret I) cartridge in object no 94 and its completion in object no 95 , on the third line.

- On the fourth line, the cartridge of King (Khabar Ka-Ra) appears in object No. 94, and it is completed in object No. 95, despite the loss of Sun symbol Ra.

- The cartridge of King (Senusret 1) appears on the fifth line in object No. 94, and its completion in object No. 95 on the same line.

Furthermore, the archaeological study showed that the object No. 96 is complementary to the object No. 95 (See Figure 6) it is showed that:

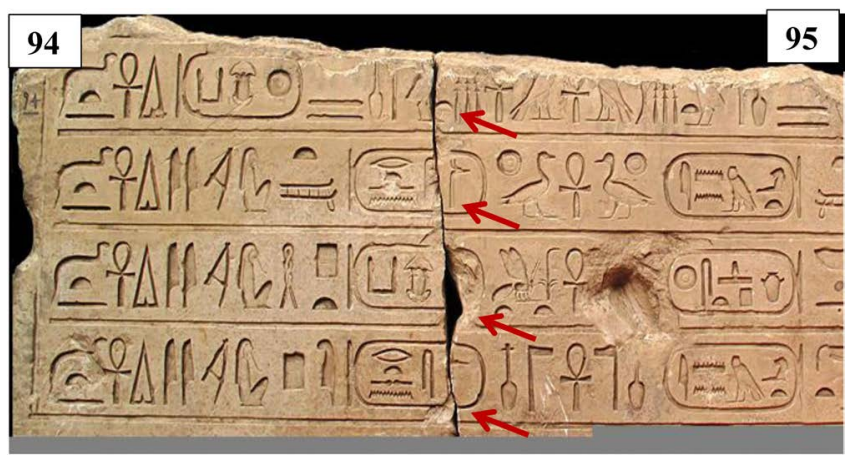

Figure 5. Shows the extent to which the hieroglyphic texts correspond in artifacts 94 and 95. 


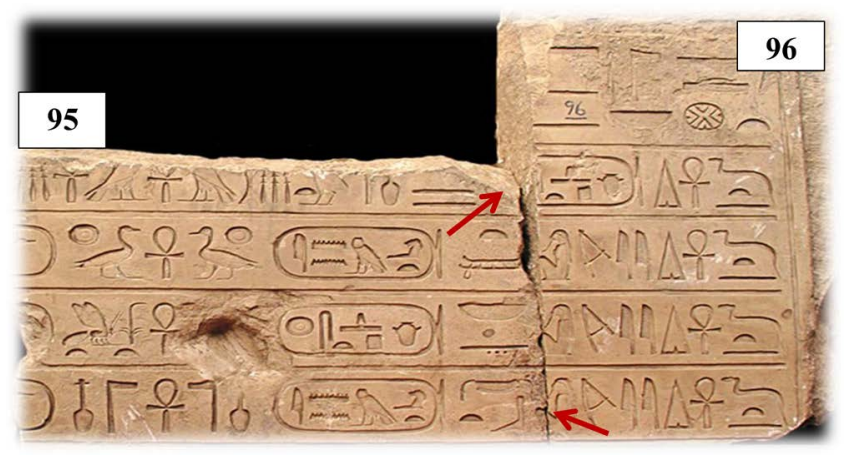

Figure 6. Shows the extent to which the hieroglyphic texts correspond in artifacts 95 and 96.

- Supplement the cartridge (Ahtab Ib Ra) in two stone objects.

- The icon of the deity on the fifth line in object No. 96 is a supplement to it in object number 95 .

\subsubsection{Translation of Hieroglyphic Texts into Arabic Using the Sesh Program}

The translation of the hieroglyphic texts shows that the text is contained within one frame that represents the "Wass" sign, where the text is bordered by "Wass" sign from two sides; end up from the top with the mark of heaven. Mostly, the two signs represented the pillars of the sky, and most often, there was above the text of the winged sun disk the symbol of the god Horus Al-Bahdati (lost).

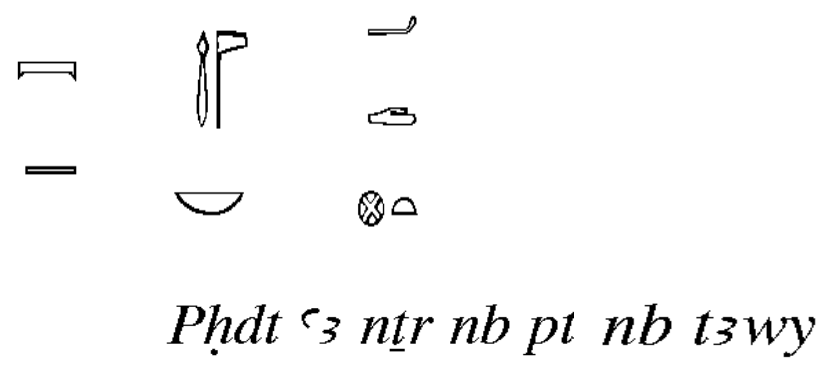

- The great idol Horus Edfu, master of heaven and earths.

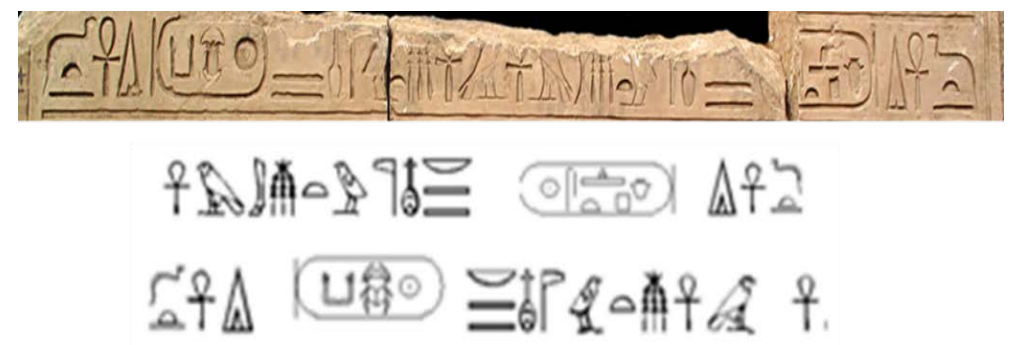

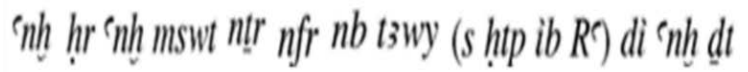

'nh hr 'nh mswt nfr ntr nb tzwy (hpr k3 R') di 'nh dt

- Long live Horus (Wehm Masot) Renewed idol, the beautiful and good idol master of the two lands, Hethab Ip Ra (Amenemhat 1), he may give life forever. 
- Long live Horus Ankh Mesut (born from life), the beautiful idol, master of the two lands, the news of $\mathrm{Ka} \mathrm{Ra}$ (Senusret 1), so that he may give life forever.

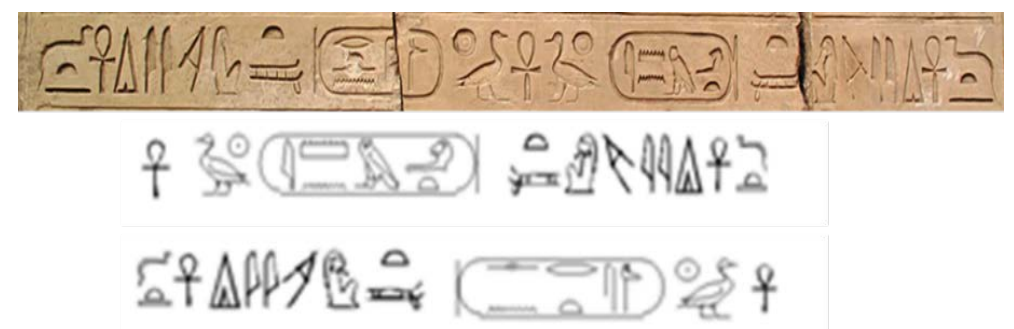

'nh s; Re (Imn m ḥ t) mry tm di 'nh dt

\section{'nh s3 R' (sn wsrt) mry tm di 'nh dt}

- Long live Ibn Ra Amenemhat 1, beloved Atum, so that he may give life forever.

- Long live Ibn Ra, Senusret 1, loved by Atum, that he may give life forever.

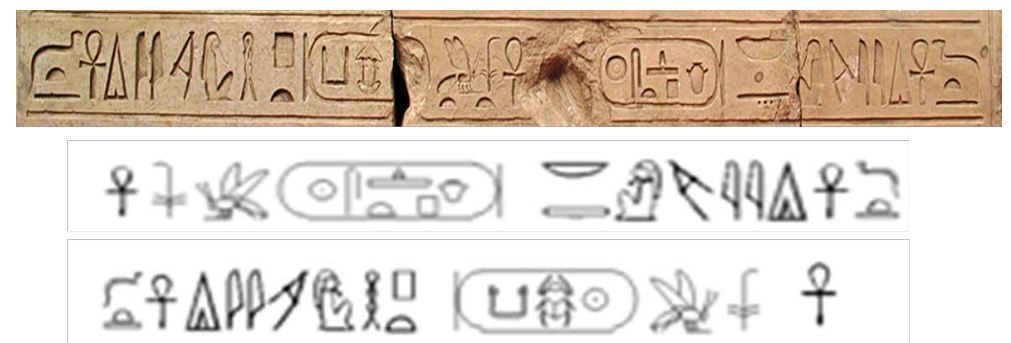

'nh ny swt-bit (s htp ib R') mry $\mathrm{Nb}$ t3 di enh dt 'nh ny swt-bit (hpr k3 R')mry Pth di 'nh dt

- Long live the king of Upper and Lower Egypt, Heptepiah of Ib-Re (Amenemhat 1), beloved of the master of the earth (the god Jeb), so he may give life forever.

- Long live the king of Upper and Lower Egypt, Khabar Ra (Senusret 1), loved by Ptah, so he can give life forever.

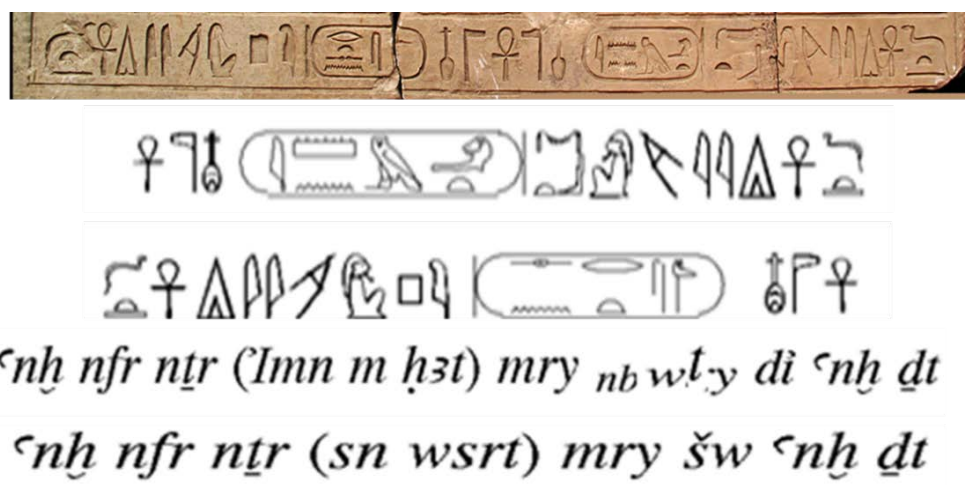

- Long live the beautiful good idol Amenemhat (the first), Mahboub Noubti (= 
Set), so that he may give life forever.

- Let the beautiful, good idol Senusert (I) live, likable to give life forever.

\subsubsection{The Most Important Results of the Archaeological Study}

- Identical style of writing in the three pieces, as well as the direction of reading, and the text is read from the middle, towards the right and on the same line to the left beginning from the mark of life (the ankh), This method was not widespread in the ancient Egyptian language throughout the ages, and it appeared clearly in the façades of the temples, which is an elaborate classic writing that distinguished the Middle Kingdom and knew precisely its mark and beauty.

- The lines are complementary to each other, and the text consists of five lines of hieroglyphic inscription engraved with bas-relief.

- Through this, it becomes clear that the total text is one text inscribed on the cornice of the entrance to a temple, and parts of the text were lost from above.

- This text is a document that indicates the existence of a common judgment between Amenemhat the First and his son Senusret the First and this was confirmed by the ancient story of Snohe.

\subsection{Results of analytical study}

\subsubsection{Mineralogical Composition: Investigation by Polarizing Microscope (PLM)}

Thin-section investigation of three limestone samples from studied objects (No 94, 95, 96) was sectioned and mounted on a microscopic slide. The results showed that the three lime stone samples consist mainly of fine-grained calcite crystals, the investigation also showed that calcite crystals interfaced in some places with quartz grains, and the grains are bounded together by iron oxides, moreover, there is a high ratio of organic materials and various fossils, furthermore, this type of limestone is characterized by its high porosity (See Figure 7)

\subsubsection{SEM-EDX Investigation}

SEM micrographs of the three samples in (Figure 8), which were carefully
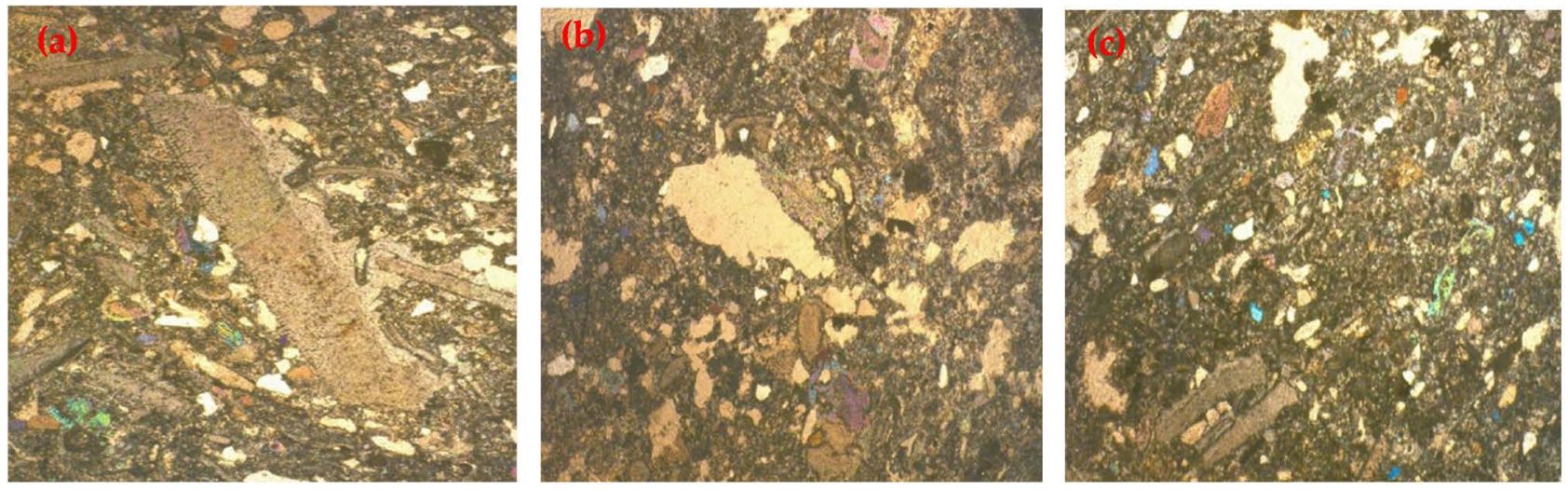

Figure 7. PLM micrographs (100x) of limestone samples (a) Sample of object No. 94 (b) Sample of object No. 95 (c) Sample of object No. 96. 

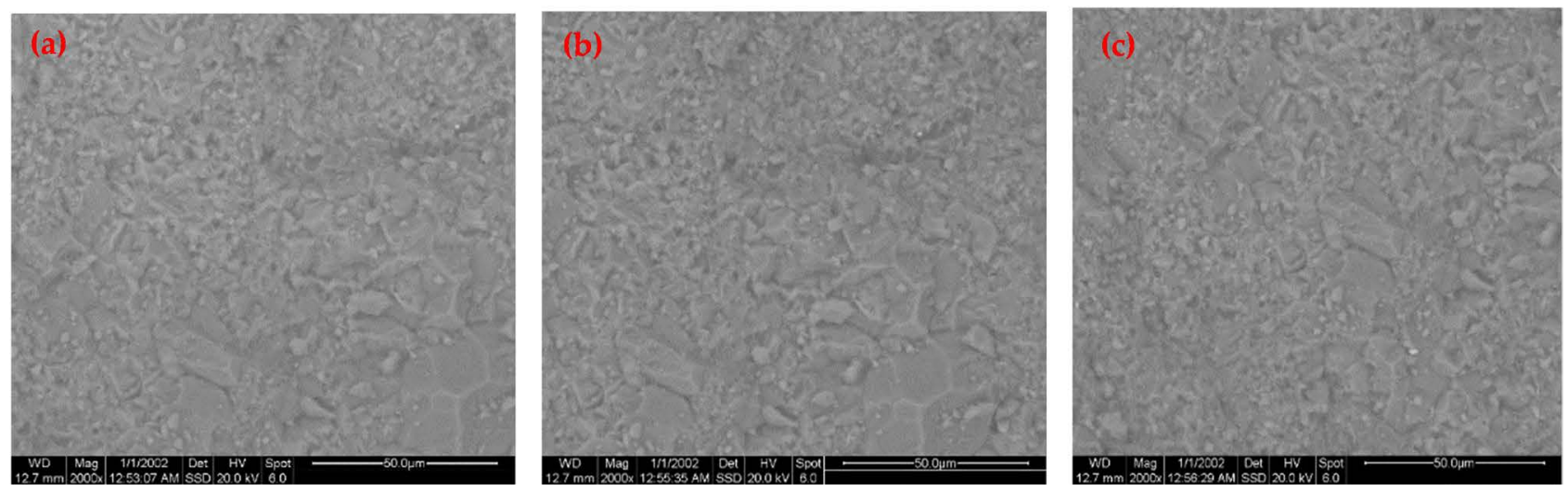

Figure 8. SEM micrographs $(2000 \times)$ of limestone samples (a) Sample of object No. 94 (b) Sample of object No. 95 (c) Sample of object No. 96.

collected from studied archaeological limestone objects (No 94, 95, 96), showed a large similarity between the three samples, it was also observed that the samples in general are in good condition, except some weathered areas in limestone texture, and this is evidenced by the presence of some voids in stone structure, moreover, it was observed the high porosity of limestone, and the disintegration of calcite crystals in some areas of stone is due to degradation by physical weathering [5].

The total EDX analysis of three limestone samples in (Figure 9) showed that stone object No (94) consists of silicon ( $\mathrm{Si}$ ) and calcium (Ca), is the dominant elements, while sulfur $(\mathrm{S})$, magnesium $(\mathrm{Mg})$, potassium $(\mathrm{K})$, aluminum $(\mathrm{Al})$ were also observed. While the total EDX analysis of stone object No (95) showed that calcium (Ca) were slightly higher than the previous sample, while silicon $(\mathrm{Si})$, sulfur(S), iron $(\mathrm{Fe})$ and magnesium $(\mathrm{Mg})$ minerals were less compared to the previous sample. Moreover, the total EDX analysis of stone object No (96) showed that the sample contains very high ratios of calcium $(\mathrm{Ca})$ as dominant element, in addition to small ratios of silicon $(\mathrm{Si})$, and magnesium $(\mathrm{Mg})$ as impurities. Through the examination, it was found that the three samples combined in most of the components, with slight differences in the proportions of each component.

\subsubsection{The Most Important Results of the Analytical Study}

Through the analytical study of stone objects, which was performed through the examination using Polarizing Microscope (PLM), and Scanning Electron Microscope SEM equipped with Energy Dispersive X-Ray Spectroscopy (SEM-EDX), to detect the element contents of archaeological limestone samples, and to identify the properties of studied stone and the existing deterioration aspects, it was observed that the three selected archaeological limestone objects consist of the same elements and have the same properties, This confirms that the three objects are complementary to each other.

\section{Re-Assembly and Conservation Processes}

The re-assembly process of the three stone objects was started based on the 


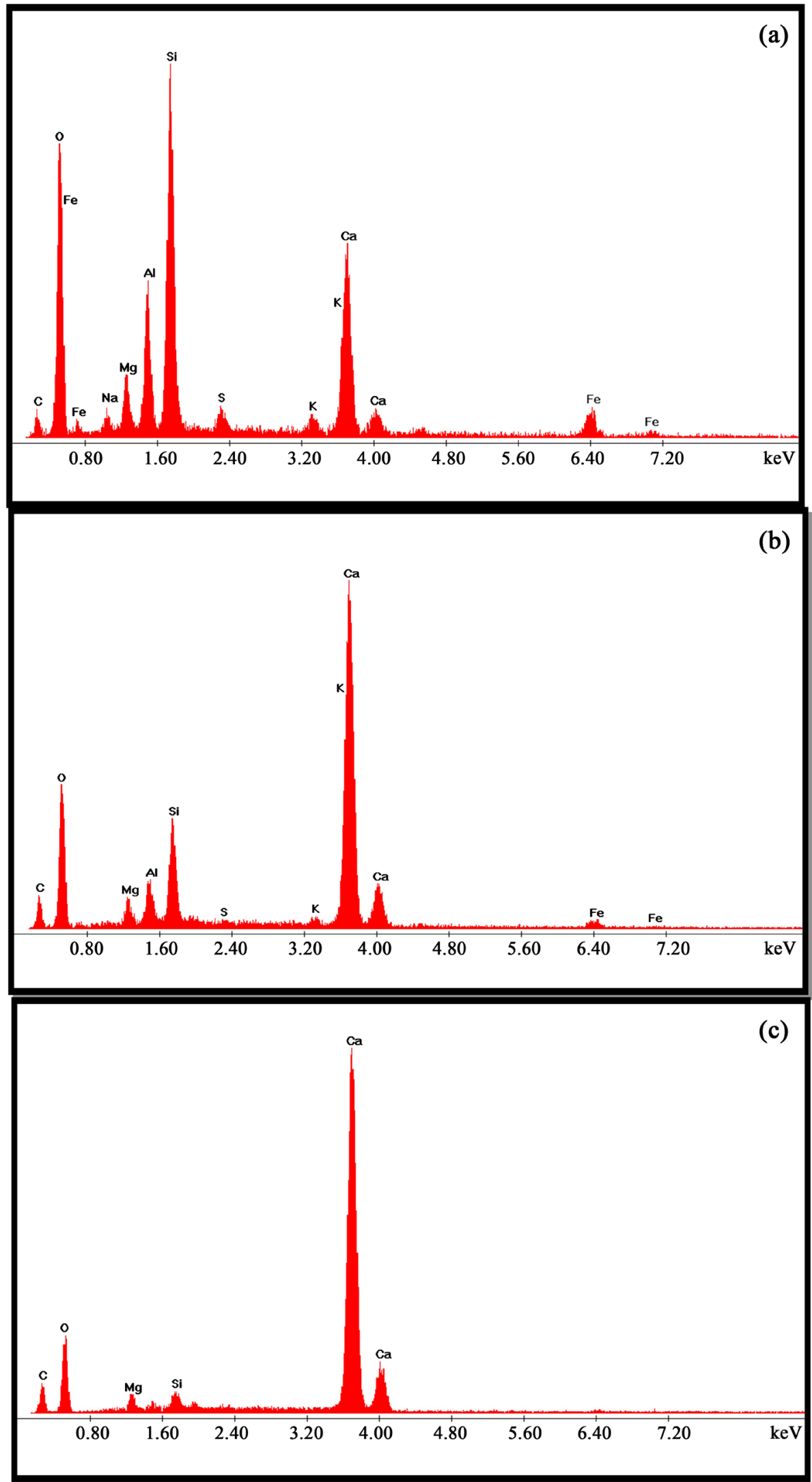

Figure 9. EDX spot analyses of the archeological studied limestone (a) Sample of object No. 94 (b) Sample of object No. 95 (c) Sample of object No. 96. 
archaeological and analytical study results, which confirmed that these three pieces of stone in the original were one piece. The re-assembly process included a series of preliminary studies as follow:

\subsection{Accurate Visual Inspection}

The conservation team responsible for the re-assembly process performed an accurate visual inspection of the three stone objects (see Figure 10), the team confirmed that these three pieces are originally one block, and the separation was made perhaps during transportation, or "breakage" as a result of exposure to the soil pressure or anywhere else, it was also found that the three pieces were carved from the limestone of light white color, and this is evidence of the stone being free of various mineral impurities.

\subsection{Observation of the Fracture Separator and Match the Edges of the Pieces Together}

By observing the fracture separation between the three stone objects, and matching the edges to each other (See Figure 11, and Figure 12) it was observed that the fracture, mostly, caused by side pressures on these pieces. Furthermore, it was observed a perfect matching between the edges of the three stone objects.

\subsection{Studying the Compatibility of Hieroglyphics Texts with Each Other}

The edges matching process has proven that the hieroglyphic texts match when the pieces are placed next to each other, and this is shown by matching the separate cartridges with each other (See Figure 13, and Figure 14).

\subsection{Architectural Documentation of the Stone Objects Using AutoCAD Program}

Before starting the final re-assembly of the stone objects, the dimensions and sizes of the three stone pieces were measured by using measurement tools, then documented using AutoCAD program, the hieroglyphic texts and cartridges were documented and drawn. Moreover, the damage symptoms on the stone surface were documented, and marked by own symbol (See Figure 15).
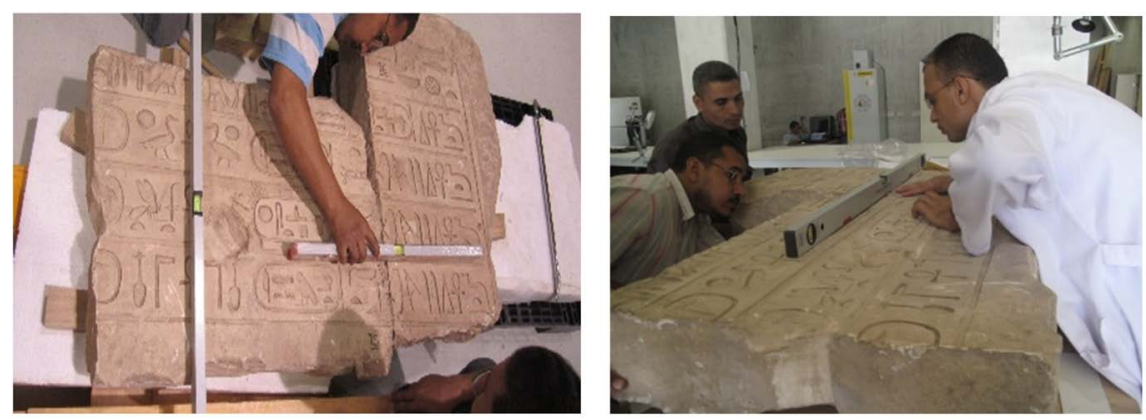

Figure 10. Visual inspection of the archeological limestone objects. 

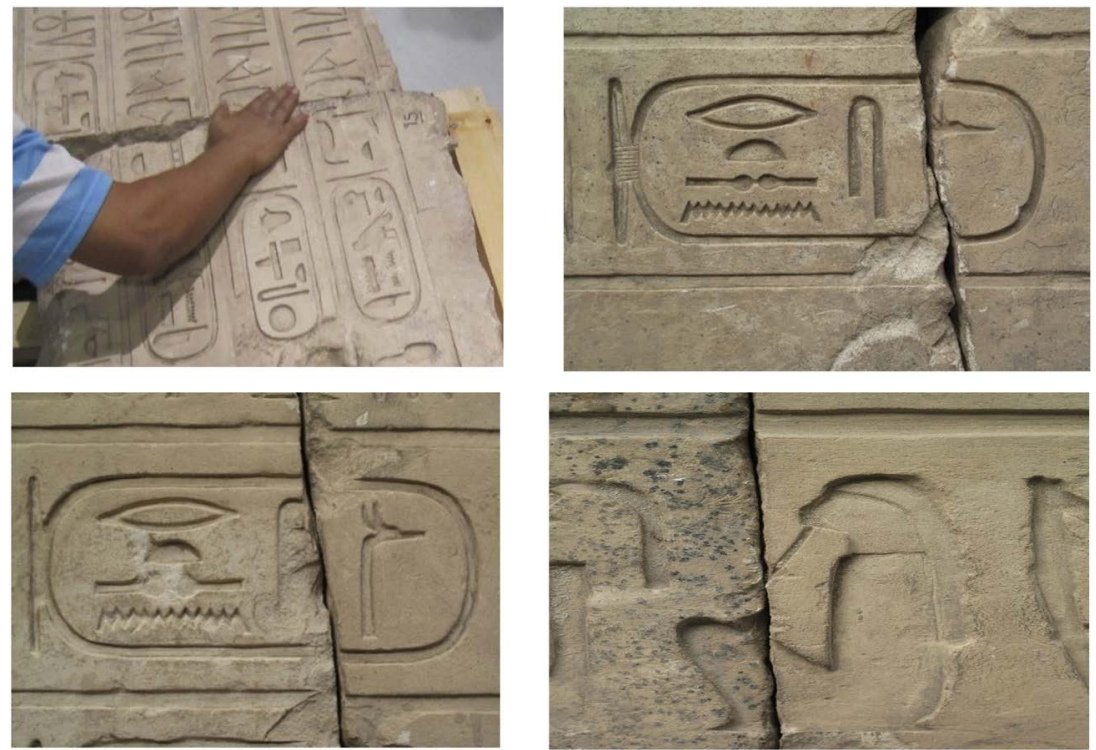

Figure 11. The fracture separator, edges emulation and matching the letters in objects No. 94 , and 95.
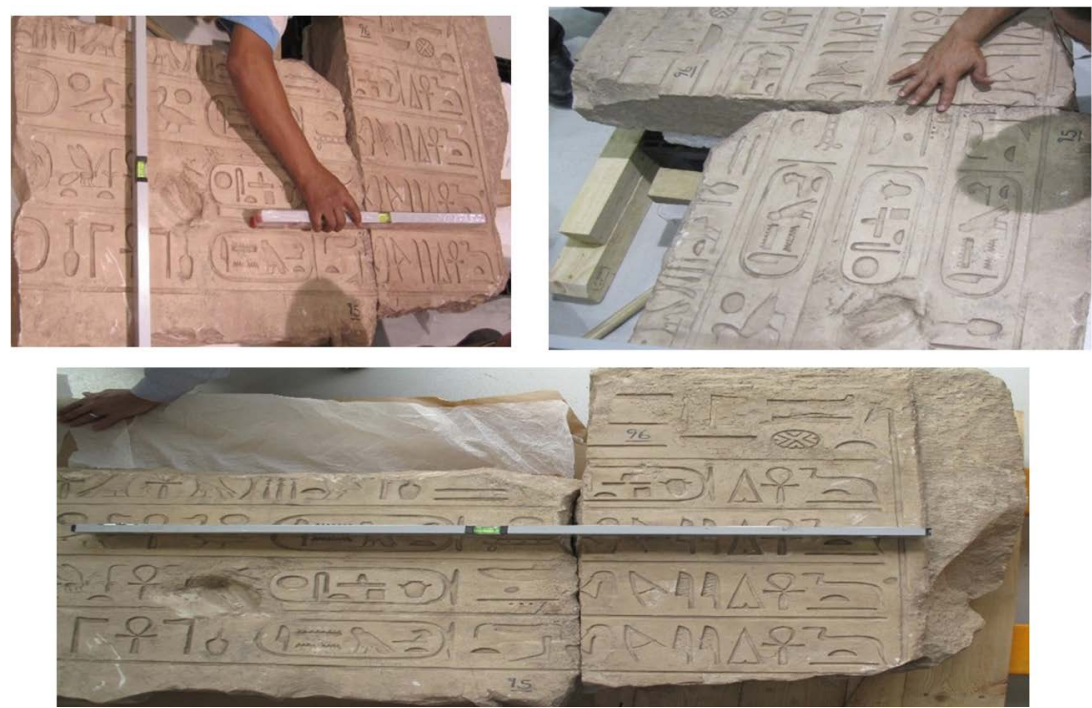

Figure 12. The fracture separator, edges emulation and matching the letters in objects No. 95, and 96.

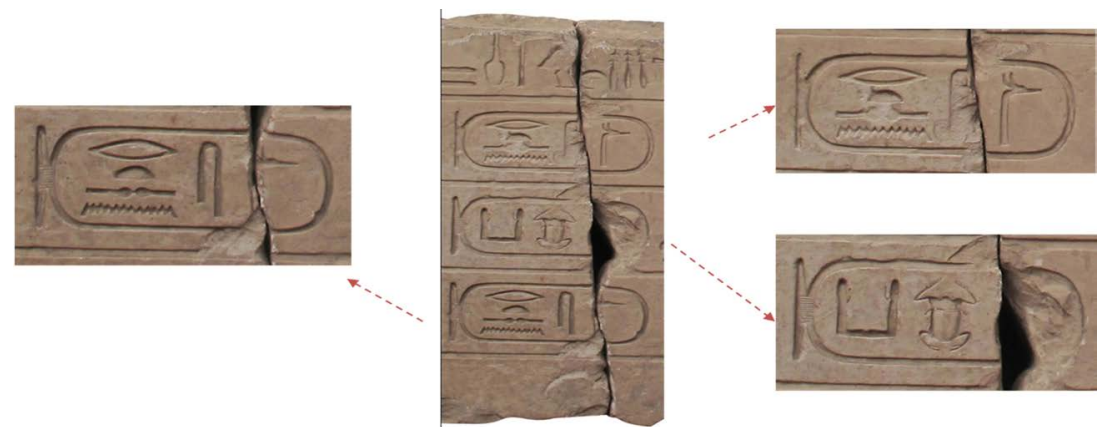

Figure 13. Shows the three separate cartridges in objects no (94) and (95) that matched perfectly during the re-assembly process. 

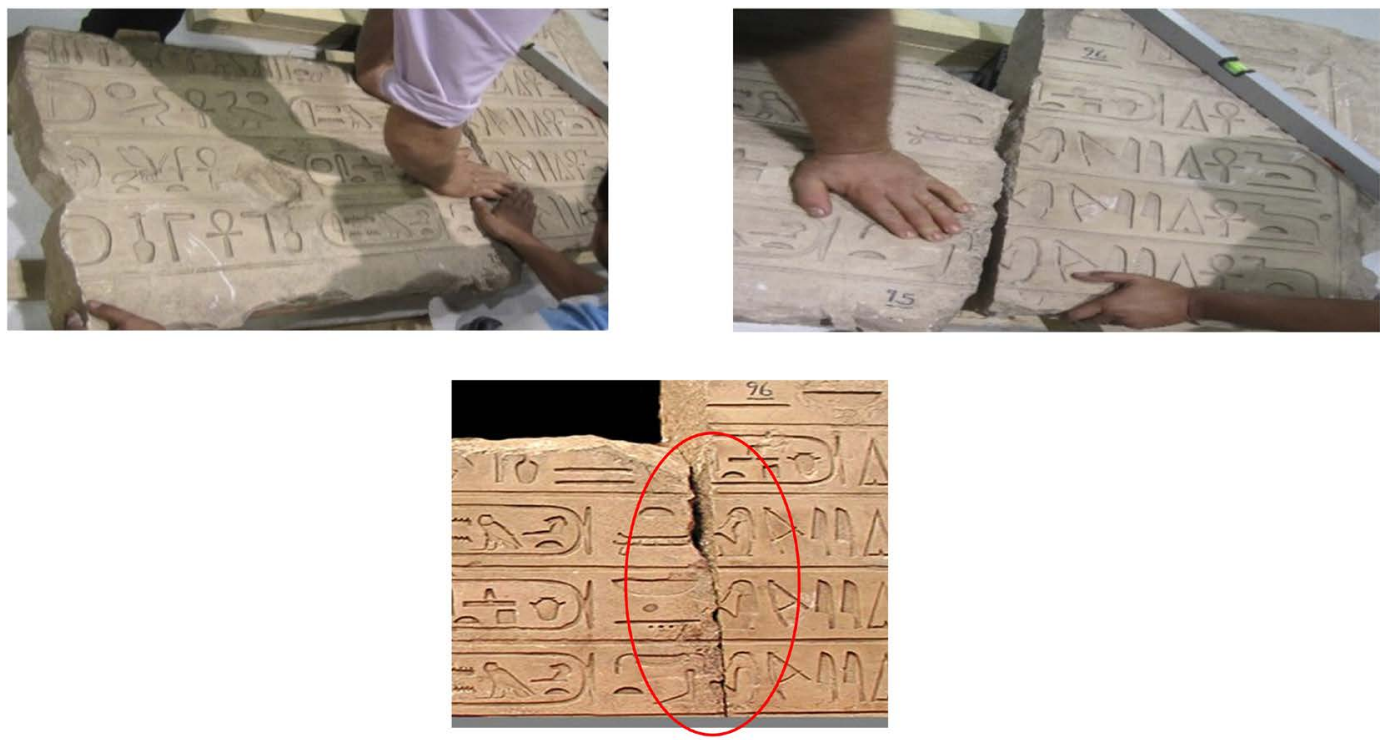

Figure 14. Shows hieroglyphic texts in objects no (94) and (95) that matched perfectly during the re-assembly process.

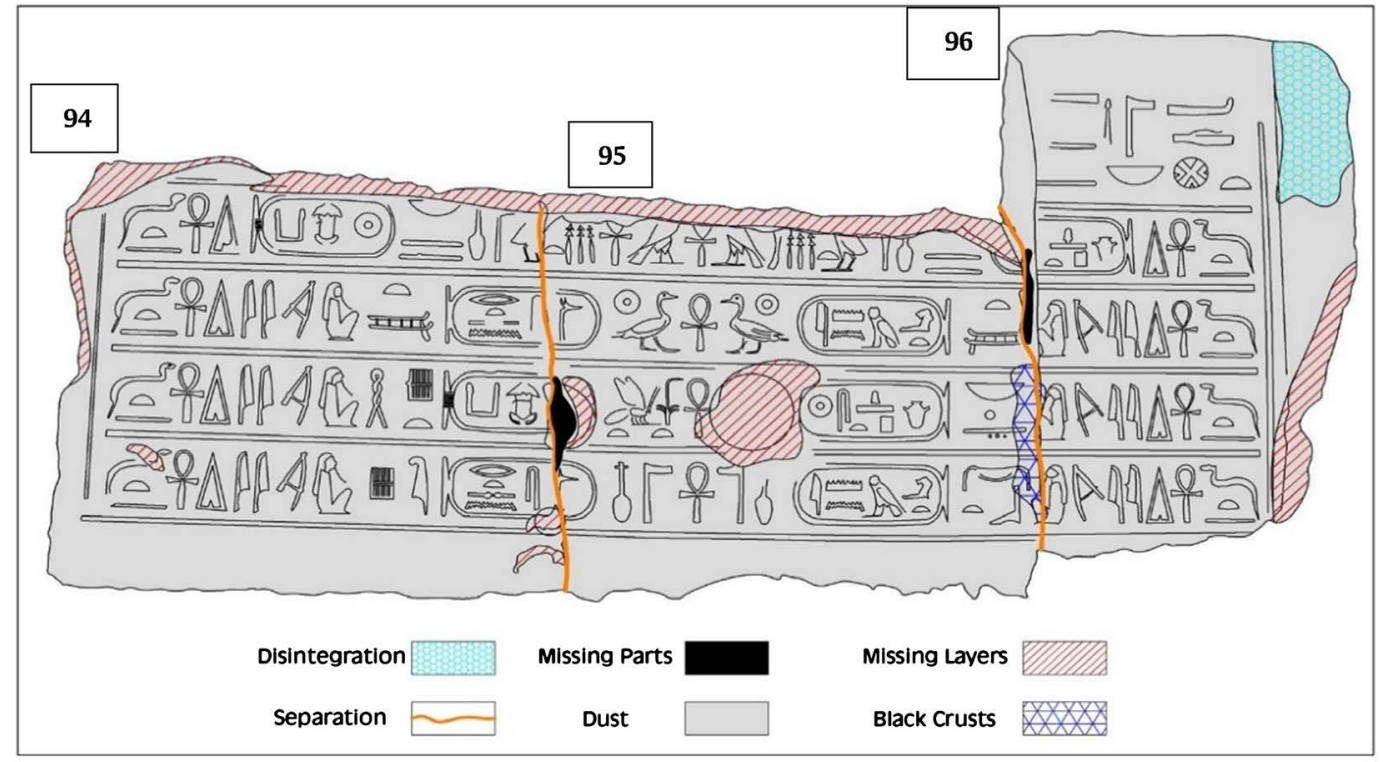

Figure 15. Shows Architectural documentation of the stone objects using AutoCAD program.

\subsection{Re-Assembly Process of the Stone Objects}

After completing the preliminary archaeological, analytical and documentation study, the stage of re-assembling the three stone objects with each other has begun, according to the international Charters [6], and by using special materials, tools and equipments suitable for heavy stone weights. Before starting the adhesive and re-assembly process, there have been some preliminary studies to determine the type of stainless steel bars used for re-assembly, and used adhesive material as mentioned in part 1 and how to apply it. These preliminary studies are explained as follow: 


\subsubsection{Precision the Balance Using the Laser Scale}

The laser scale was used to locate and adjust the holes for inserting the assembly stainless steel bars, in addition to measuring and determining the distances between each hole and the other with extreme accuracy (see Figure 16).

\subsubsection{Implementation of the Hole Places and Determining the Depths within the Stone}

After locating the holes points, two holes were made in each object, with a depth of $17 \mathrm{~cm}$ from each direction. Electric drill was used to make the holes, with caution so as not to affect the stones through vibration during the work, in addition to taking into account the accuracy in the implementation of holes according to the places previously determined through the laser scale. Stainless steel bars of $12 \mathrm{~mm}$ diameter were used, knowing that determining the number of Stainless steel bars, the depth of holes inside the stone, and the thickness of the bars depends mainly on the weight, thickness, and condition of the stone object to be re-assembly (see Figure 17).

\subsubsection{Preparation of Stainless Steel Bars}

The stainless steel bars used in the re-assembly process were cut and equipped according to the specified sizes and thickness, then inserted and fixed into the stone according to the specified depth (see Figure 18, and Figure 19).

\subsubsection{Final Re-Assembly of the Stone Objects}

After finishing the preparation and inserting of stainless steel bars, the re-assembly
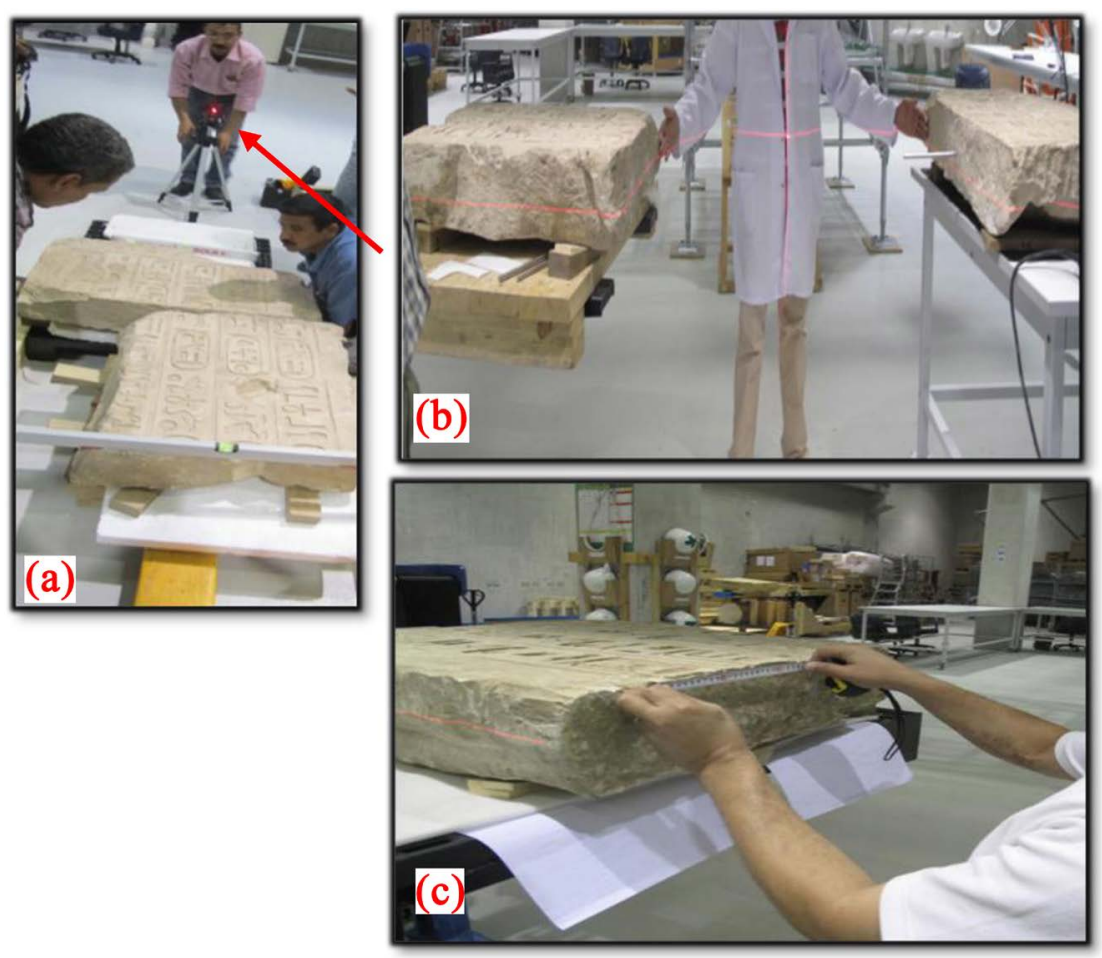

Figure 16. ((a) \& (b)) Using laser scale to adjust the balance of the objects as a prelude to re-assembly, (c) Measuring and determining the distances between each hole and the other. 

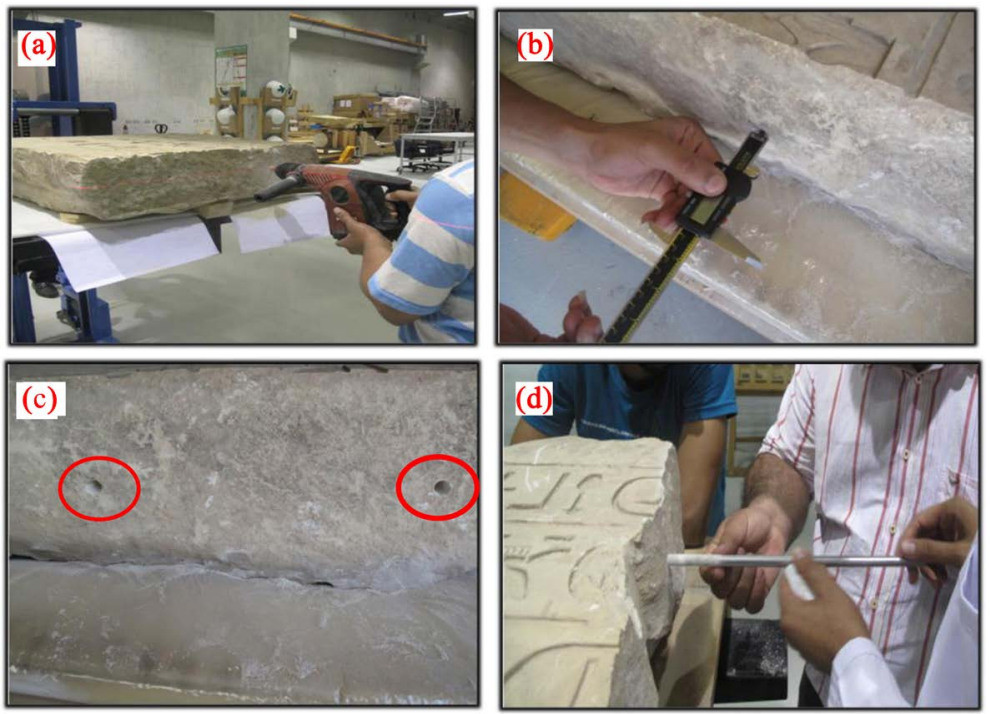

Figure 17. Implementation of the holes and determining the depths within the stone (a) Using drill to make holes (b) Using electronic measurement to determine the depth of holes (c) The holes after implementation at the specified depth (d) Use stainless steel bars with $12 \mathrm{~mm}$ diameter.
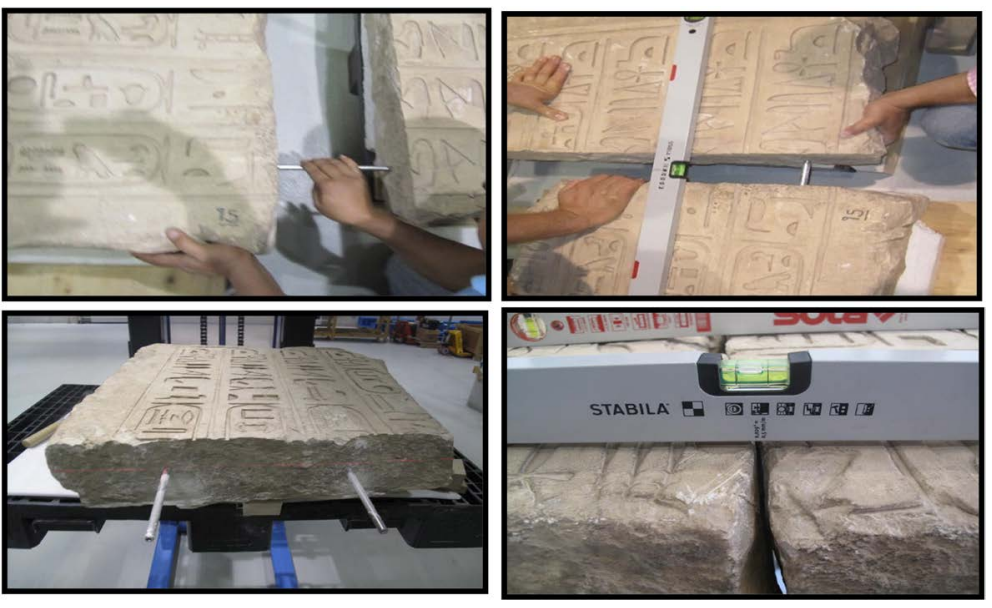

Figure 18. Steps of inserting stainless steel bars inside the stone objects.

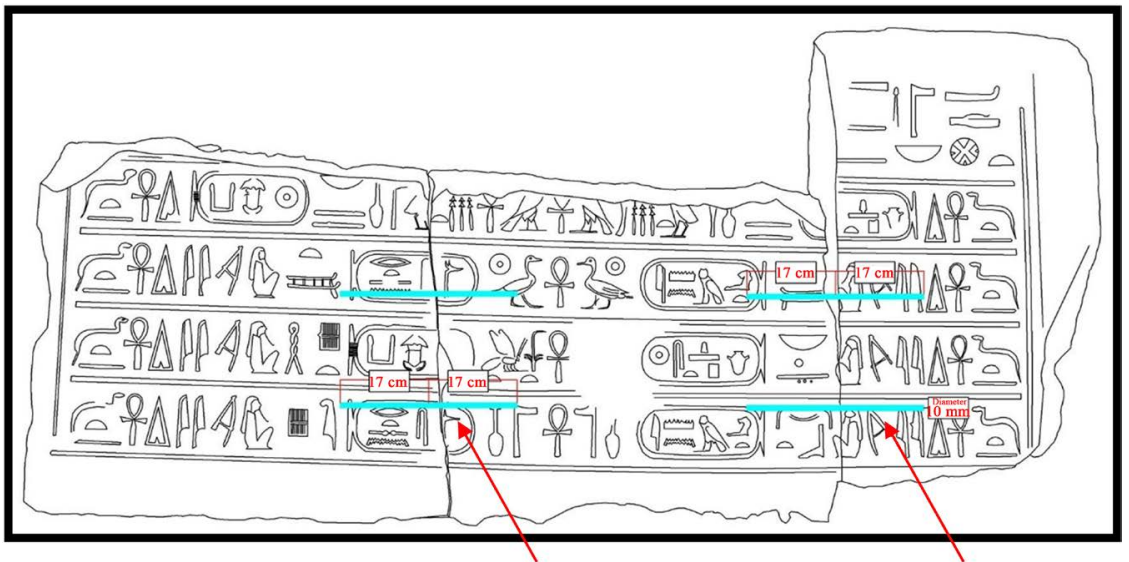

Figure 19. A drawing shows the method of inserting stainless steel bars inside the stone. 
process has started by applying the adhesive material together with the stainless steel bars, and based on the obtained results in part 1, the choice fell on epoxy-clay nanocomposites as the best adhesive material, when reinforced with stainless steel bars (See Figure 20, and Figure 21).

\subsubsection{Conservation Processes}

After completing the Re-assembly process of the three stone objects, the
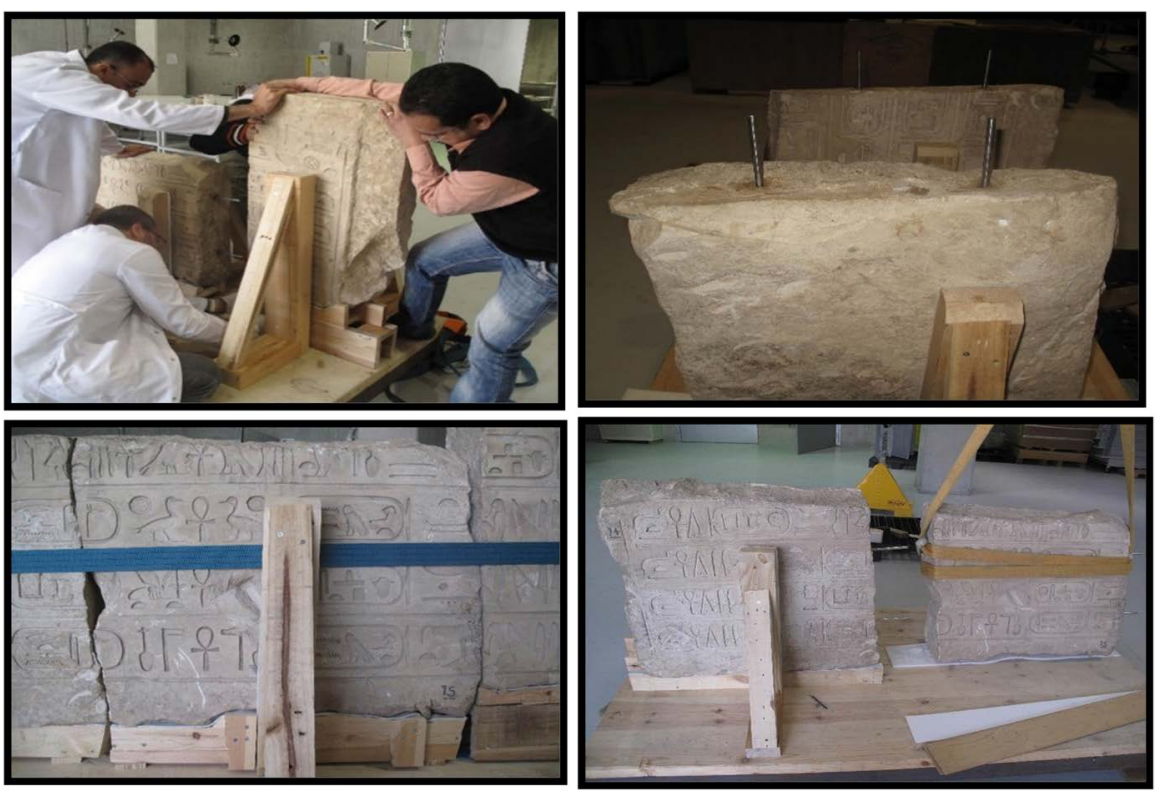

Figure 20. Use soft skis and wooden molds that are designed to use in moving stone objects during final re-assembly.
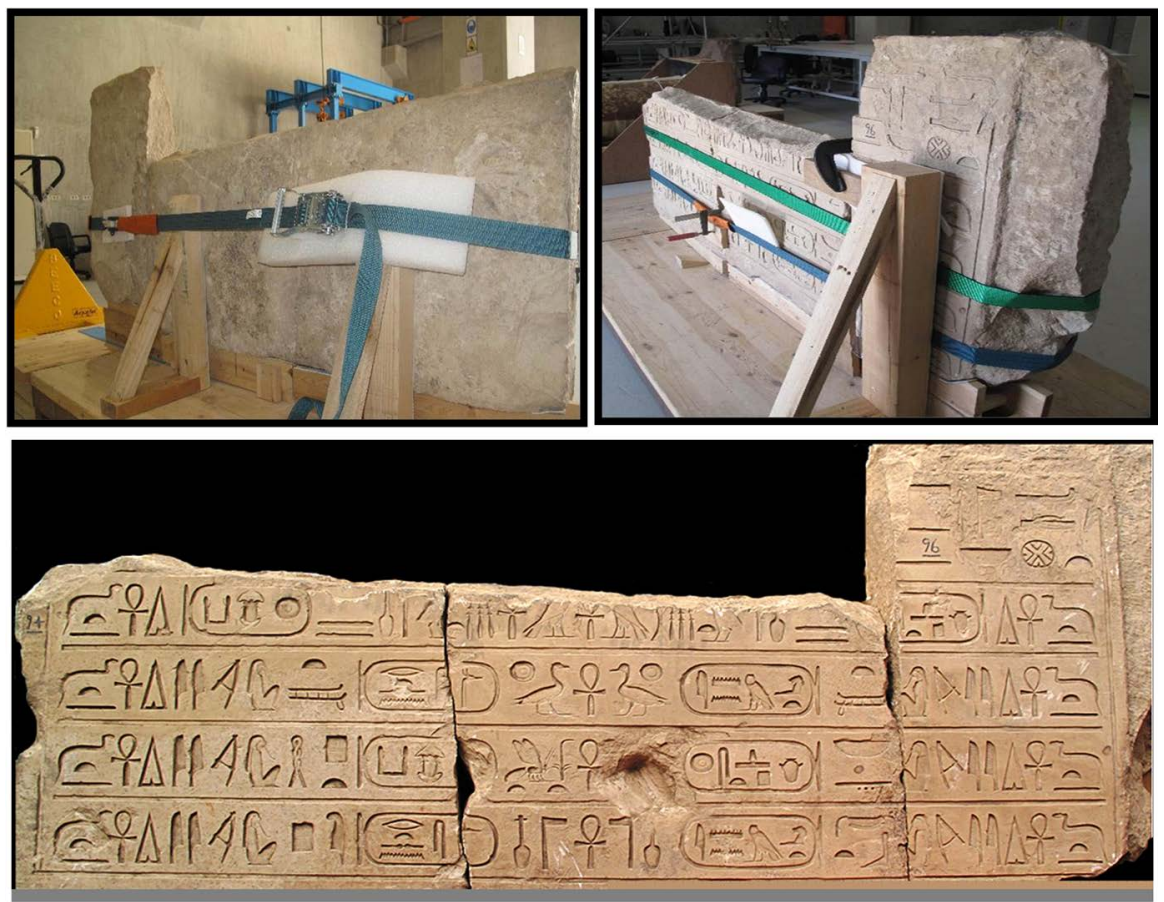

Figure 21. The three stone objects after completing final re-assembly. 
conservation process has started, with consideration that the stone objects in good condition, the aim of the conservation process is just to remove dust and dirt from the stone surface, and consolidate some of weak areas of the stone edges. The conservation process includes mechanical cleaning using soft brushes, scalpels, metal and wood spatula for removing dusts, stains, and any impurities on the stone surface, This is followed by chemical cleaning using some organic solvents such as deionized water and ethyl alcohol, in order to remove the remaining difficult stains and dirts, after that, consolidation of the weak points of stone edges using Paraliod B72 (2\%) was carried out [7] (See Figures 22-25).

\section{Conclusion}

This study focused on the possibility to apply the results obtained in the experimental part of the study (Part 1), which confirmed the effectiveness of epoxy-clay nanocomposites as the re-assembly adhesive material reinforced with stainless
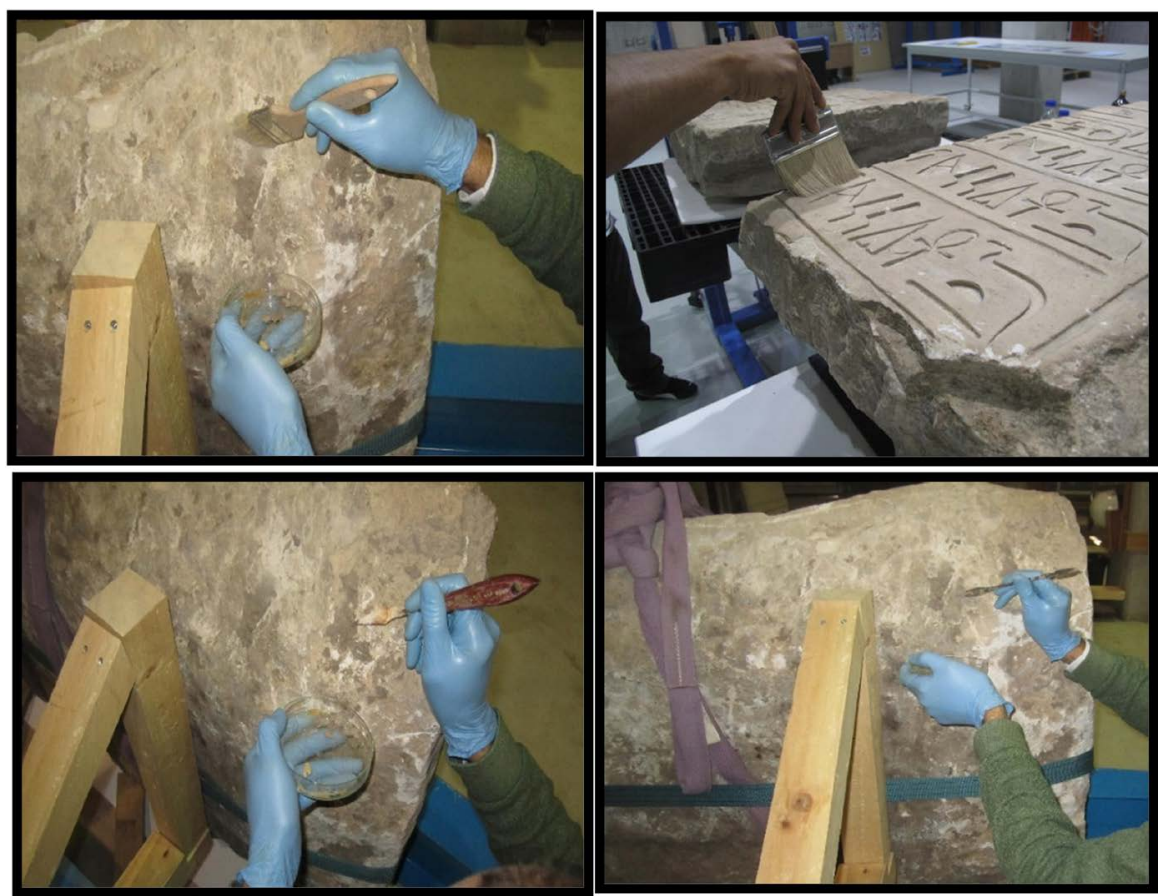

Figure 22. Part of the mechanical cleaning of the stone objects.
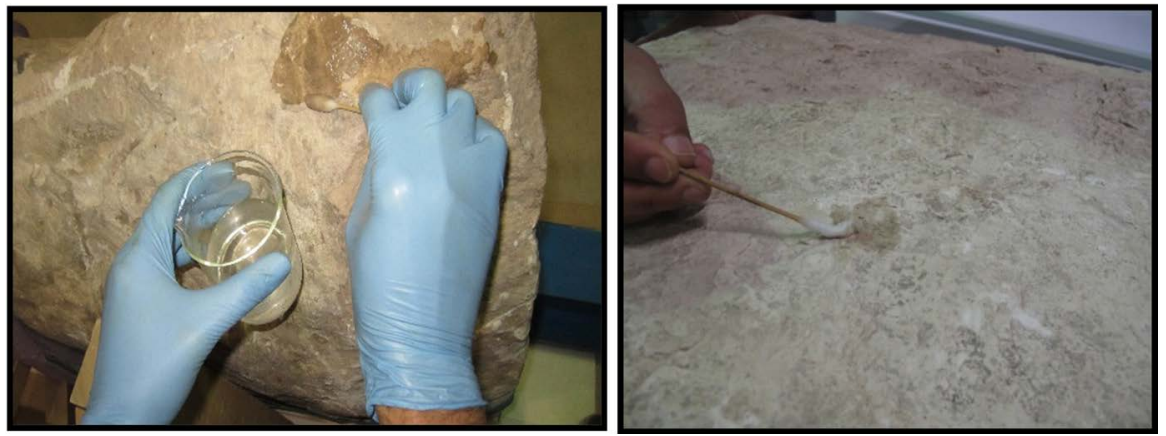

Figure 23. Part of the chemical cleaning of the stone objects. 

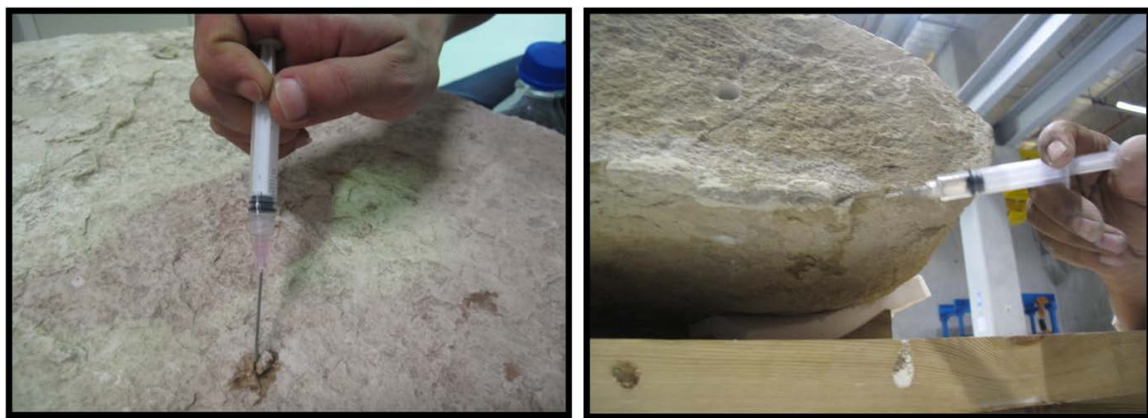

Figure 24. Consolidation of the weak points of stone edges.
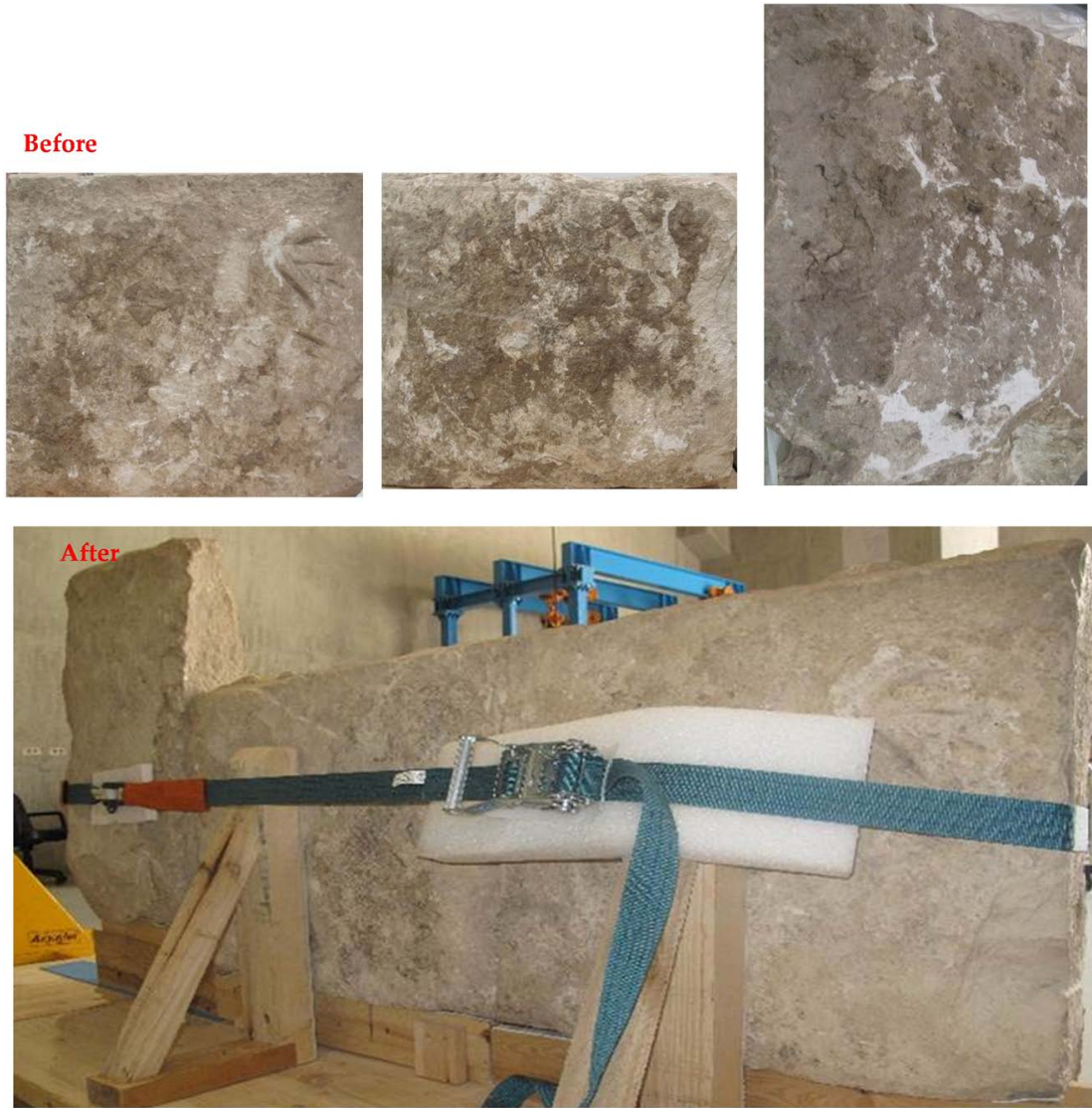

Figure 25. The three stone objects before and after re-assembly and conservation processes.

steel for re-assembling archaeological massive limestones. The applied study relied on a scientific methodology to re-assembly of the massive stone monuments that were subjected to separation as a result of exposure to different deterioration agents, where the study included an accurate archaeological, analytical and conservation study before starting the re-assembly process. Preliminary studies that preceded the re-assembly process confirmed that these pieces of stone in the original were one piece, and there was the possibility of regrouping again to become one block complementary to each other. The re-assembly process was carried out with high technology and skill, according to the standard specifications for this purpose, using epoxy-clay nanocomposites and stainless steel bars. 


\section{Acknowledgements}

The authors would like to express their gratitude sincere to King Abdulalziz City for Science and Technology (KACST), Riyadh, Saudi Arabia for the valuable and continuous scientific and moral support. Great thanks and appreciation to archaeologists team and Specialists in the ancient Egyptian language in Grand Egyptian Museum for helping us with archaeological study and translation of hieroglyphic texts.

\section{Author Contributions}

Sawsan S. Darwish, Sayed M. Ahmed, and Mohammad A. Aldoasri conceived and designed the experiments; Sayed M. Ahmed and Mahmoud A. Adam performed the experiments; Sawsan S. Darwish, Nagib A. Elmarzugi, and Mahmoud A. Adam analyzed the data; Mohammad A. Aldoasri and Nagib A. Elmarzugi contributed reagents/materials/analysis tools; Sawsan S. Darwish, Mahmoud A. Adam and Sayed M. Ahmed conceived conservation procedures, wrote and review the paper.

\section{Conflicts of Interest}

The authors declare no conflicts of interest regarding the publication of this paper.

\section{References}

[1] Aldoasri, M.A., Darwish, S.S., Adam, M.A., Elmarzugi, N.A. and Ahmed, S.M. (2020) Re-Assembly of Archaeological Massive Limestones Using Epoxy Resin Modified With Nanomaterials-Part 1: Experimental. Green and Sustainable Chemistry, 10, 24-38. https://www.scirp.org/journal/gsc https://doi.org/10.4236/gsc.2020.101003

[2] Abd el-Gelil, M., Shaker, M. and Raue, D. (1996) Recent Excavations at Heliopolis. Orientalia, 65, 136-146.

[3] Bloch, H.P. and Geitner, F.K. (2005) Machinery Component Maintenance and Repair. Elsevier, Gulf Professional Pub, Amsterdam, London, 66.

[4] Rabilloud, G. (1997) High Performance Polymers, Chemistry and Application. In: Conductive Adhesives, Vol. 1, Editions Technip, 31.

[5] Aldoasri, M.A., Darwish, S.S., Adam, M.A., Elmarzugi, N.A. and Ahmed, S.M. (2019) Using ZnO Nanoparticles in Fungal Inhibition and Self-Protection of Exposed Marble Columns in Historic Sites. Archaeological and Anthropological Sciences, 11, 3407-3422. https://doi.org/10.1007/s12520-018-0762-Z

[6] Icomos, C. (2003) Principle for the Analysis, Conservation and Structural Restoration of Architectural Heritage. ICOMOS 14th General Assembly in Victoria Falls, Zimbabwe, 27-31 October 2003.

[7] Aldoasri, M.A., Darwish, S.S., Adam, M.A., Elmarzugi, N.A. and Ahmed, S.M. (2019) Evaluation of Preventive Performance of Kaolin and Calcium Hydroxide Nanocomposites in Strengthening the Outdoor Carved Limestone. Archaeological and Anthropological Sciences, 11, 3389-3405.

https://doi.org/10.1007/s12520-018-0741-4 